\section{TÀI LIÊU THAM KHẢO}

1. Trương Phạm Ngọc Đăng, Nguyễn Văn Ân, Nguyễn Ngọc Châu (2015), "Đánh giá hiệu quá của tán sỏi thân qua da bằng siêu âm trong sỏi bán san hô", Y hợ TP. Hồ Chí Minh, tâp 19, số 1,17-23.

2. Nguyễn Hoàng Đức, Nguyển Tậ̂n Cương, Trân Lê Linh Phương (2007), "Phẫu thuật lấy sỏi thân qua da", Ngoai khoa tâp 57, tr. 35-41.

3. Rassweiler J.J, C. Renner And F. Eisenberger (2000). The management of complex renal stones. BJU International (2000), 86, 919-928

4. Pierre A. Clavien, Jeffrey Barkun, Michelle L. de Oliveira (2009), "The Clavien-Dindo Classification of Surgical Complications Five-Year Experience", Annals of Surgery, Volume 250, Number 2, August 2009
5. Hoàng Long và CS (2016), "Kết quả tán sỏi thân qua da bằng holmium laser tai bênh viện đai hoc Y Hà Nội", Y học Việt Nam. 445, tháng 8, số đă̆c biệt, tr. 62-71.

6. Ahmed R. El-Nahas, Ibrahim Eraky, Ahmed A. Shokeir (2012). Percutaneous nephrolithotomy for treating staghorn stones: 10 years of experience of a tertiary-care centre. Arab Journal of Urology 10, 324-329

7. Võ Phước Khương, (2012), "Lây sỏi qua da với đường vào thâan tữ đài dưới trong điêu trị sỏi thân phức tap", Y học TP. Hồ Chí Minh phụ bản số 3, 203-207.

8. Shun-Kai Chang, Ian-Seng Cheong. Pressure compression of the cccess tract for tubeless percutaneous nephrolithotomy. Urol Sci, 30, 19-23.

\title{
THỰC TRẠNG VĂN HOÁ AN TOÀN NGƯỜI BÊNHH CỦA NHÂN VIÊN Y TẾ BỆNH VIỆN ĐA KHOA LÂM ĐỒNG II, NĂM 2019
}

\section{TÓM TẮT}

Việc xác định thực trạng văn hóa an toàn người bênh giúp cho thức hiên an toàn người bênh tai cớ sở y tế được tốt hơn. Nghiên cứu này được thực hiện vớ muc tiêu mô tả thực trang văn hóa an toàn người bệnhcủa nhân viên y tế bệnh viên II Lâm Đồng, năm 2019. Thiết kế nghiên cứu mô tả cắt ngang, sử dung phương pháp kết hợp định lượng và định tính. Thờ gian thức hiên từ tháng 2 đến tháng 9/2019 tai bênh viện II Lâm Đ̇ồng. Bộ câu hỏi của cơ quan Nghiên cứu y tế và chất lượng Hoa Kỳ đo lường 12 lĩnh vực văn hóa an toàn người bệnh đã được sử dụng cho nghiên cứu định lượng trên 357 nhân viên y tế (NVYT) và tiến hành 8 cuộc phỏng vấn sâu cho nghiên cứu định tính. Kết quả cho thấy: Hầu hết lãnh đạo các khoa phòng quan tâm công tác an toàn người bệnh (ATNB); Đa số NVYT có tinh thần làm viêc nhóm, tự học hỏi và hỗ trơ xử trí các vấn đề ATNB trong khoa; 1/3 NVYT cho rằng khoa phòng mình có vấn đề về ATNB; Công tác phản hồi về những sai sót,tỉ lệ trao đổi cởi mở về ATNB và báo cáo sai sót còn chưa nhiêu; Làm việc nhóm giữa các khoa chưa thuận lợi; 1/2 NVYT lo ngai khi bàn giao chuyển người bệnh khi xảy ra sự cố; xấp Xỉ 50\% NVYT đánh giá khoa phòng minh là an toàn; Chỉ 1/3 NVYT thực hiện báo cáo sự cố. Nghiên cứu khuyến nghi cần xây dựng môi trường làm việc tâp trung vào yếu tố $A T N B$, đặc biệt khuyến khích công tác báo cáo sự cố, tâp trung xây dựng các quy trình phối hợp công tác giữa các khoa phòng. Từ khoá: văn hoá an toàn người bệnh, bệnh viện, nhân viên y tế

${ }^{1}$ Trường Đại học Y tế công cộng

2Bênh viên đa khoa II Lâm Đồng

Chịu trách nhiệm chính: Nguyễn Ngọc Bích

Email: nnb@huph.edu.vn

Ngày nhân bài: 5.4.2021

Ngày phản biên khoa hoc: 25.5.2021

Ngày duyệt bài: 7.6.2021

\section{Nguyễn Ngọc Bích ${ }^{1}$, Huỳnh Ngọc Thành ${ }^{2}$ \\ SUMMARY}

PATIENT SAFETY CULTURE AMONG HEALTH WORKERS OF LAM DONG II HOSPITAL, 2019

Patient safety culture awareness and improvement helps managers to improve the patient safety at the hospital. This study aimed to investigate the situation of patient safety cultute at Lam Dong II hospital in 2019.This cross sectional study was conducted from February to September, 2019 using both quantitative and qualitative methods. The tool was NIH questionnaire including 12 sections on patient safety. 357 health workers participated to the quantitative study and 8 indept interviews were implemented. Results show that almost head of departments of the hospital cared about the patient safety. The majority of health workers was good in team work, self learning and support team members. One third of health workers considered that their departments had patient safety problems. Report on medical problems, open discussion were the issues of patient safety culture of the hospital. Only $50 \%$ of health workers think that their departments were safe for patient and only one third of health workers reported their medical faults. It was recommended that the hospital should encourage their workers to report medical faults and develop procedure for that. Keywords: patient safety culture, health workers, hospital

\section{I. ĐĂT VẤN ĐỀ}

Nguyên tắc quan trong nhất của thực hành y khoa là "Điều đầu tiên không gây tổn hại cho người bệnh - First Do No Harm to patient" đang là điều trăn trở đối với các cơ sở, đơn vị Y tế cũng như người hành nghề khám chữa bênh (KCB).

Ủy ban Chất lượng DVYT thuộc Viện Y khoa Hoa Kỳ đưa ra 6 mục tiêu của một DVYT đảm bảo chất lượng, đó là: "An toàn (Safe), Hiệu quả 
(Effective), Người bệnh làm trung tâm (Patientcentred), Kịp thời (Timely), Hiệu suất (Efficient) và Công bằng (Equitable)". Trong đó, "An toàn" cho người bệnh (NB) là mục tiêu quan trọng nhất (1).

Tại Việt Nam trong những năm qua với sự phát triển của truyền thông và các trang mạng xã hội thì sự cố y khoa (SCYK) được công chúng đặc biệt quan tâm. Khi nghiên cứu về nguyên nhân SCYK, người ta thấy rằng một số sự cố có thể chủ động phòng tránh được (2), (3), (4), (4). Để đảm bảo chất lượng DVYT mà trong đó mục tiêu "an toàn" cho NB được xem là quan trọng nhất cần thay đổi quan điểm "văn hóa trừng phạt" sang "văn hóa an toàn (VHAT)" trong các cơ sở khám bệnh, chữa bệnh (3), (5)Khi NVYT có văn hóa đúng về an toàn người bệnh (ATNB) thì mới có thể cung cấp các DVYT chất lượng vì con người là yếu tố nền tảng cho thành công trong mọi hệ thống y tế (4), (6)

Nghiên cứu được tiến hành với mục tiêuMô tả thực trạng văn hóa an toàn người bệnh của nhân viển y tế bệnh viện II Lâm Đồng, năm 2019.

\section{II. ĐỐI TƯợNG VÀ PHƯƠNG PHÁP NGHIÊN CỨU \\ 2.1 Đối tượng nghiên cứu \\ * Nghiên cứu định lượng \\ - Tất cả nhân viến y tế (NVYT) trực tiếp liên quan đến bệnh nhân: Là các $B S, \mathrm{DD}, \mathrm{HL}$ \\ - Tất cả NVYT gián tiếp liên quan đến bệnh nhân: Là các kỹ thuật viên, BS Cận lâm sàng, nhân viên khoa dược \\ - Lãnh đạo (LĐ) Bệnh viện, LĐ các khoa phòng \\ *Nghiên cứu định tính \\ - Đại diên LĐ Bênh viện \\ - Đại diện LĐ các khoa phòng \\ - Đại diện NVYT: Bác sĩ, Điêu dưỡng, hộ lý}

2.2. Phương pháp nghiên cứu. Phương pháp nghiên cứu mô tả cắt ngang tiến hành song song kết hợp định lượng và định tính

2.3. Cỡ mẫu. Chọn mẫu toàn bộ 390 nhân viên y tế tham gia chăm sóc người bệnh trực tiếp và gián tiếp. Tổng số thu thập được 357 phiếu của 357 nhân viên $Y$ tế

2.4 Phương pháp chọn mẫu: chọn mẫu toàn bô

Định tính: Nhằm làm rõ bổ sung cho kết quả nghiên cứu định lượng và tìm ra các yếu tố liên quan VHATNB của NVYT tại Bệnh viện. Chọn mẫu có chủ định những đối tượng cung cấp nhiều thông tin nhất. Tiến hành 8 cuộc phỏng vấn sâu (PVS) cho các đại diện như sau:

- 01 đại diện LĐ Bệnh viện: Phó Giám đốc phụ trách quản lý chất lượng bệnh viện.

- 03 đại diện LĐ của đơn vị: 01 trưởng khoa hệ ngoại, 01 trưởng khoa xét nghiệm, 01 trưởng khoa dược. Sở dĩ chọn các khoa này là do trong các cuộc giao ban chuyên môn hàng ngày thường bị nhắc nhở về sự cố y khoa, về kết quả xét nghiệm không chính xác, không tương thích với lâm sàng, về thiếu thuốc và vật tư, về thuốc tác dụng kém, vật tư tiêu hao chất lượng không đạt.

- 03 đại diện NVYT: 01 bác sĩ khoa ngoại, 01 điều dưỡng khoa nội, 01 kỹ thuật viên chẩn đoán hình ảnh, 01 hộ lý khoa nội.

2.4. Địa điểm, thời gian nghiên cứu

- Đia điểm: Bênh viện II Lâm Đồng

-Thời gian: Từ tháng 2/2019 đến tháng 9/2019

\subsection{Bộ công cụ nghiên cứu}

Định lượng: Sử dụng bộ câu hỏi (phụ lục 2) khảo sát VHATNB của AHRQ (Hospital Survey on Patient Safety Culture - HSOPSC) đã được Sở Y tế thành phố Hồ Chí Minh dịch ta tiếng Việt và áp dụng cho các BV trong thành phố. Bộ công cụ này bao gồm 42 tiểu mục được chia làm 12 nhóm yếu tố và 2 tiểu mục đâu ra (outcome), cụ thể là:

+ Làm việc nhóm trong khoa phòng gồm 4 tiểu mục

+ Quan điểm và hành động ATNB của LĐ gồm 4 tiểu mục

+ Hoc tập và cải tiến liên tục gồm 3 tiểu mục

+ Hổ trợ xử trí các vấn đề ATNB gồm 3 tiểu mục

+ Quan điểm chung về ATNB gồm 4 tiểu mục

+ Phản hồi và trao đổi về những sai sót gồm

3 tiểu mục

+ Trao đổi cởi mở gồm 3 tiểu mục

+ Báo cáo sai sót gồm 3 tiểu mục

+ Làm việc nhóm giữa các khoa/phòng gồm

4 tiểu mục

+ Bảo đảm nguồn nhân lực gồm 4 tiểu mục

+ Bàn giao và chuyển người bệnh gồm 4 tiểu mục

+ Văn hóa không đổ lỗi khi có sai sót gồm 3 tiểu mục

\subsection{Biến số nghiên cứu}

- Đặc điểm chung của đối tượng nghiên cứu

- Biến số về văn hoá an toàn người bệnh theo các tiểu mục

\subsection{Phương pháp thu thập số liệu}

- Thu thập thông tin theo phương pháp dùng phiếu điều tra ẩn danh được in sẵn bộ câu hỏi cho đối tượng nghiên cứu trả lời.

- Thành lập nhóm nhân viên thu thập thông tin được tập huấn về phương pháp thu thập số liệu và nội dung bảng câu hỏi, đảm bảo hiểu đúng nội dung từng tiểu mục.

- Thồng báo cho nhân viền toàn viện về nghiên cứu này trong toàn viện qua giao ban và email.

- Nhân viên thu thập số liệu đến từng khoa phòng giới thiệu về nghiên cứu, công bố nguyên 
tắc tham gia nghiên cứu (không được bàn bạc khi đánh trắc nghiệm trên phiếu điêu tra, không được đánh trắc nghiệm thay, đánh trắc nghiệm theo đúng suy nghĩ và thực tế tại khoa phòng, giải thích cho NVYT về tính khách quan và không bị liên lụy cá nhân khi điền phiếu điều tra) phát phiếu điều tra cho từng NVYT, nhân viên y tế đọc và điền thông tin theo mấu. Nhân viên thu thập thu thông tin giải thích những câu hỏi chưa rõ cho NVYT khi có thắc mắc. Thu thập phiếu điều tra sau khi NVYT hoàn thành.

2.8. Xử lý số liệu. Sử dụng phần mềm spss 20.0 để nhập và xử lý thống kê. Kết quả trình bày theo bảng tân số, tỷ lệ, giá trị trung bình

2.9. Vấn đề đạo đức trong nghiên cứu. Nghiên cứu được tiến hành theo Quyết định số 247/2019/YTCC-HD3 về việc chấp thuận các vấn đề đạo đức NCYSH của Hội Đồng đạo đức trong nghiển cứu y sinh học trường Đại Học YTCC cho đề tài này.

\section{KẾT QUẢ NGHIÊN CỨU}

Bảng 3.1. Thông tin chung về đối tượng nghiên cứu ( $N=357)$

\begin{tabular}{|c|c|c|}
\hline Thông tin & Tân suất & Tỷ lệ \\
\hline \multicolumn{3}{|c|}{ Khoa phòng } \\
\hline Cận lâm sàng & 52 & 14,6 \\
\hline Dược & 19 & 5,3 \\
\hline Phòng khám - cấp cứu & 34 & 9,5 \\
\hline Nội nhi, nhiềm, PHCN & 120 & 33,6 \\
\hline Vgoại sản và mắt RHM, TMH & 132 & 37,0 \\
\hline \multicolumn{3}{|c|}{ Thâm niên công tác } \\
\hline Dưới 1 năm & 17 & 4,8 \\
\hline $1-10$ năm & 165 & 46,2 \\
\hline Trên 10 năm & 175 & 49,0 \\
\hline \multicolumn{3}{|c|}{ Thời gian làm việc trong tuần } \\
\hline Dưới 40 giờ & 10 & 2,8 \\
\hline $40-<80$ giờ & 291 & 81,5 \\
\hline$>80$ giơ̌ & 56 & 15,7 \\
\hline
\end{tabular}

3.2. Thực trang văn hóa an toàn người bệnh

Bảng 3.2. Tỷ lệ các tiểu mục thuộc yếu tổ "Làm việc nhóm trong khoa phòng"

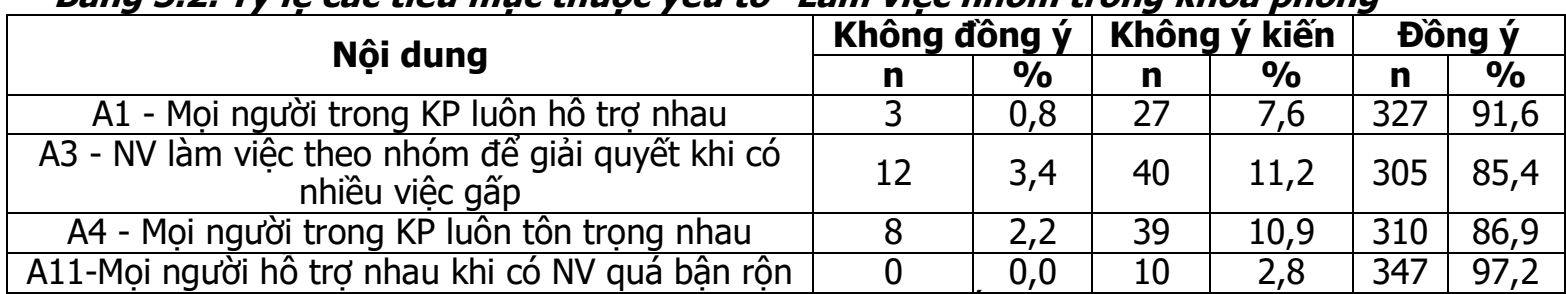

Đa số mọi người có tinh thần làm việc nhóm: Với 91,6\% Y kiến NVYT đồng ý "mọi người trong khoa phòng luôn hỗ trợ nhau" (A1); 85,4\% ý kiến đồng ý "làm việc theo nhóm để giải quyết khi có nhiêu việc gấp" ( $\mathrm{A} 3) ; 86,9 \%$ đồng ý "mọi người trong khoa phòng luôn tôn trọng nhau" (A4) và $97,2 \%$ đồng ý mọi người hỗ trợ nhau khi có nhân viên quá bận rộn (A11).

Bảng 3.3Tỷ lệ các tiểu mục thuộc yếu tố "Quan điểm và hành động ATNB của LĐ"

\begin{tabular}{|c|c|c|c|c|c|c|}
\hline \multirow{2}{*}{ Nội dung } & \multicolumn{2}{|c|}{ Không đồng ý } & \multicolumn{2}{|c|}{ Không ý kiến } & \multicolumn{2}{|c|}{ Đồng ý } \\
\hline & $\mathbf{n}$ & $\%$ & $\mathbf{n}$ & $\%$ & $\mathbf{n}$ & $\%$ \\
\hline $\begin{array}{l}\text { B1 - LĐ khoa động viên khi NV thực } \\
\text { hiện đúng quy trình ATNB }\end{array}$ & 10 & 2,8 & 32 & 9,0 & 315 & 88,2 \\
\hline $\begin{array}{c}\text { B2 - LĐ KP nghiêm túc xem xét các đề } \\
\text { xuất cải tiến ATNB của NV }\end{array}$ & 8 & 2,2 & 25 & 7,0 & 324 & 90,8 \\
\hline $\begin{array}{l}\text { B3R - LĐ KP hối thúc hoàn thành công } \\
\text { việc mà không quan tâm đến quy trình }\end{array}$ & 39 & 10,9 & 86 & 24,1 & 232 & 65,0 \\
\hline $\begin{array}{l}\text { B4R - LĐ KP không quan tâm đến } \\
\text { những sai sót lập đi lập lại }\end{array}$ & 0 & 0,0 & 17 & 4,8 & 340 & 95,2 \\
\hline
\end{tabular}

Đa số LĐ các KP có ý thức và hành động cải tiến ATNB: $88,2 \%$ ý kiến NVYT đồng ý cho rằng: "LE khoa động viên khi nhân viên thực hiện đúng quy trình ATNB" (B1), 90,8\% đồng ý cho rằng: "LĐ khoa phòng nghiêm túc xem xét các đề xuất cải tiến ATNB của nhân viên" (B2). Tuy nhiên có $65,0 \%$ ý kiến cho rằng: "LĐ KP hối thúc hoàn thành công việc mà không quan tâm đến quy trình" (B3R) và 95,2\%ý kiến cho rằng: "LĐ khoa phòng không quan tầm đến những sai sót lập đi lập lại" (B4R).

Bảng 3.4 Tỷ lệ các tiểu mục thuộc yếu tố "Học tập và cải tiến liên tục"

\begin{tabular}{|c|c|c|c|c|c|c|}
\hline \multirow{2}{*}{ Nội dung } & \multicolumn{2}{|c|}{ Không đồng ý } & \multicolumn{2}{c|}{ Không ý kiến } & \multicolumn{2}{c|}{ Đồng ý } \\
\cline { 2 - 7 } & $\mathbf{n}$ & $\mathbf{\%}$ & $\mathbf{n}$ & $\mathbf{n}$ & $\mathbf{n}$ & $\mathbf{\%}$ \\
\hline A6 - NV chủ động triến khai các hoạt & 6 & 1,7 & 32 & 9,0 & 319 & 89,4 \\
\hline
\end{tabular}




\begin{tabular}{|c|c|c|c|c|c|c|}
\hline $\begin{array}{l}\text { A9 -Sai sót giúp khoa phòng có những } \\
\text { thay đổi tích cưc }\end{array}$ & 11 & 3,1 & 51 & 14,3 & 295 & 82,6 \\
\hline $\begin{array}{l}\text { A13 - KP có đánh giá hiệu quả các biện } \\
\text { pháp cái tiến ATTNB }\end{array}$ & 4 & 1,1 & 57 & 16,0 & 296 & 82,9 \\
\hline
\end{tabular}

Đa số NVYT có tinh thần học tập cải tiến liên tục nhằm giảm thiếu sai sót và cải thiện công tác ATNB.

Bảng 3.5 Tỷ lệ các tiểu mục thuộc yếu tồ "Hỗ trợ xử trí các vấn để ATNB"

\begin{tabular}{|c|c|c|c|c|c|c|}
\hline \multirow{2}{*}{ Nội dung } & \multicolumn{2}{|c|}{ Không đồng ý } & \multicolumn{2}{|c|}{ Không ý kiến } & \multicolumn{2}{|c|}{ Đồng ý } \\
\hline & $\mathbf{n}$ & $\%$ & $\mathbf{n}$ & $\%$ & $\mathbf{n}$ & $\%$ \\
\hline $\begin{array}{l}\text { F1 - LĐ BV tạo ra bầu không khí làm việc } \\
\text { hướng đến ATNB }\end{array}$ & 15 & 4,2 & 38 & 10,6 & 304 & 85,2 \\
\hline $\begin{array}{l}\text { F8 - ATNB là ưu tiên hàng đâu trong mọi } \\
\text { hoat động BV }\end{array}$ & 12 & 3,4 & 43 & 12,0 & 302 & 84,6 \\
\hline F9R - LĐ BV chỉ quan tâm ATNB khi có sư cố & 89 & 24,1 & 79 & 22,1 & 189 & 52,9 \\
\hline
\end{tabular}

Lượng lớn NVYT cho rằng: "LĐ bệnh viện tạo ra bầu không khí làm việc hướng đến ATNB" $(85,2 \%)$ và $84,6 \%$ đồng ý cho rằng: "ATTNB là ưu tiên hàng đầu trong mọi hoạt động BV" (F8). Tuy nhiên có trên $50 \%$ cho rằng: "LĐ bệnh viện chỉ quan tâm ATNB khi có sự cố" (F9R).

Bảng 3.6 lệ các tiểu muc thuộc yếu tố Quan điểm chung về ATNB

\begin{tabular}{|c|c|c|c|c|c|c|}
\hline \multirow{2}{*}{ Nội dung } & \multicolumn{2}{|c|}{ Không đồng ý } & \multicolumn{2}{|c|}{ Không ý kiến } & \multicolumn{2}{|c|}{ Đồng ý } \\
\hline & $\mathbf{n}$ & $\%$ & $\mathbf{n}$ & $\%$ & $\mathbf{n}$ & $\%$ \\
\hline $\begin{array}{l}\text { A15 - ATNB là ưu tiên hàng đầu hơn là } \\
\text { cố gắng hoàn thành công việc }\end{array}$ & 154 & 43,1 & 26 & 7,3 & 177 & 49,6 \\
\hline $\begin{array}{l}\text { A18 - Khoa phòng có quy trình và biện } \\
\text { pháp phòng ngứa các sai sót }\end{array}$ & 3 & 0,8 & 26 & 7,3 & 328 & 91,9 \\
\hline $\begin{array}{l}\text { A10R - Khoa phòng không xảy ra sai } \\
\text { sót là do may mắn }\end{array}$ & 33 & 9,2 & 72 & 20,2 & 252 & 70,6 \\
\hline $\begin{array}{c}\text { A17R - Khoa phòng có những vấn đề } \\
\text { về ATNB }\end{array}$ & 119 & 33,3 & 105 & 29,4 & 133 & 37,3 \\
\hline
\end{tabular}

Phần đông NVYT đồng ý rằng: "Khoa phòng có quy trình và biện pháp phòng ngừa các sai sót" (A18 = 91,9\%); Gần 2/3 NVYT đồng ý với tiểu mục A10R (Khoa phòng không xảy ra sai sót là do may mắn $(70,6 \%)$; Tuy nhiên chỉ gần phân nửa NVYYT đồng ý rằng: "ATNB là ưu tiên hàng đầu hơn là cố gắng hoàn thành công việc" $(A 15=49,6 \%)$ và hơn $1 / 3$ NVYT đồng ý là: "Khoa phòng có những vấn đề về $A T N B^{\prime \prime}(A 17 R=37,3 \%)$.

Bảng 3.7 Tỷ lệ các tiếu mục thuộc yếu tố "Phản hồi và trao đổi về những sai sót"

\begin{tabular}{|c|c|c|c|c|c|c|}
\hline \multirow{2}{*}{ Nội dung } & \multicolumn{2}{|c|}{ Không đơ̂ng ý } & \multicolumn{2}{|c|}{ Không ý kiến } & \multicolumn{2}{|c|}{ Đồng ý } \\
\hline & $\mathbf{n}$ & $\%$ & $\mathbf{n}$ & $\%$ & $\mathbf{n}$ & $\%$ \\
\hline $\begin{array}{l}\mathrm{C} 1 \text { - NV trong KP đư } \\
\text { pháp khắc phuc sai }\end{array}$ & 41 & 11,5 & 120 & 33,6 & 196 & 54,9 \\
\hline C3 - NV được thông báo về những sai sót trong KP & 11 & 3,1 & 43 & 12,0 & 303 & 84,9 \\
\hline $\begin{array}{c}\text { C5 - KP có tố chức thảo luân các biện pháp phòng } \\
\text { nqứa SS tái diễn }\end{array}$ & 12 & 3,4 & 84 & 23,5 & 261 & 73,1 \\
\hline
\end{tabular}

Đã có 84,9\% NVYT các KP đồng ý: "Nhân viên được thông báo về những sai sót trong khoa phòng" (tiểu mục $\mathrm{C} 3$ ) và $73,1 \%$ cho rằng: "Khoa phòng có tổ chức thảo luận các biện pháp phòng ngừa sai sót tái diễn" (C5). Tuy nhiên chỉ có hơn phân nửa $(54,9 \%)$ cho rằng: "Nhân viên trong khoa phòng được thông báo về những biện pháp khắc phục sai sót dựa trên báo cáo sự cố" (C1).

Bảng 3.8 Tỷ lệ các tiểu muc thuộc yếu tố "Trao đổi cởi mơ"

\begin{tabular}{|c|c|c|c|c|c|c|}
\hline \multirow[t]{2}{*}{ Nội dung } & \multicolumn{2}{|c|}{$\begin{array}{l}\text { Không } \\
\text { đồng ý }\end{array}$} & \multicolumn{2}{|c|}{$\begin{array}{l}\text { Không ý } \\
\text { kiến }\end{array}$} & \multicolumn{2}{|c|}{ Đông ý } \\
\hline & $n$ & $\%$ & $\mathbf{n}$ & $\%$ & $\mathrm{n}$ & $\%$ \\
\hline $\begin{array}{l}\text { C2 - NV trong KP thoải mái trao đối về những vấn } \\
\text { đề ảnh hưởng không tốt đến chăm sóc NB }\end{array}$ & 37 & 10,4 & 108 & 30,3 & 212 & 59,4 \\
\hline $\begin{array}{c}\text { C4 - NV thoải mái khi chất vấn các quyết định về } \\
\text { ATNB của LĐ }\end{array}$ & 91 & 25,5 & 142 & 39,8 & 124 & 34,7 \\
\hline $\begin{array}{c}\text { C6R - NV trong KP ngại có ý kiến khi thấy có những } \\
\text { vân đề về ATNB }\end{array}$ & 72 & 20,2 & 151 & 42,3 & 134 & 37,5 \\
\hline
\end{tabular}

Hơn 1/3 NVYT không có ý kiến với tiếu mục: "NV thoải mái khi chất vấn các quyết định về ATNB 
của $L \Xi^{\prime \prime}(C 4=39,8 \%)$ và vẫn còn số lượng lớn NV trong KP ngại có ý kiến khi thấy có những vấn đề về ATNB (C6R = 37,5\%). Đồng thời cũ̃ng chỉ có 59,4\% đồng ý với tiểu mục C2 (NV trong KP thoải mái trao đổi về những vấn đề ảnh hưởng không tốt đến chăm sóc NB).

\section{Bảng 3.9. Tỷ lệ các tiểu muc thuộc yêu tố "Báo cáo sai sót"}

\begin{tabular}{|c|c|c|c|c|c|c|}
\hline Nội dung & \multicolumn{2}{|c|}{ Không bao giờ } & \multicolumn{2}{c|}{ Đôi khi } & \multicolumn{2}{c|}{ Thường xuyên } \\
\cline { 2 - 7 } & $\mathbf{n}$ & $\mathbf{\%}$ & $\mathbf{n}$ & $\mathbf{\%}$ & $\mathbf{n}$ & $\mathbf{\%}$ \\
\hline $\begin{array}{c}\text { D1 - BC sai sót xảy ra nhưng được phát hiện } \\
\text { và ngăn chănn trước khi ảnh hưởng đến NB }\end{array}$ & 32 & 9,0 & 103 & 28,9 & 222 & 62,1 \\
\hline $\begin{array}{c}\text { D2 - BC sai sót xảy ra nhưng không có khả } \\
\text { năng gây hại cho NB }\end{array}$ & 37 & 10,4 & 126 & 35,3 & 194 & 54,3 \\
\hline $\begin{array}{c}\text { D3 - BC sai sót có thế gây hại cho NB } \\
\text { nhưng may mắn không gầy hại }\end{array}$ & 38 & 10,6 & 84 & 23,5 & 235 & 65,9 \\
\hline
\end{tabular}

Tỷ lệ NVYT tiến hành "Báo cáo sai sót xảy ra nhưng được phát hiện và ngăn chặn trước khi ảnh hưởng đến NB" và "Báo cáo sai sót xảy ra nhưng không có khả năng gây hại cho NB" chưa cao (D1 $=62,1 \% ; \mathrm{D} 2=54,3 \%$ ). Đối với các Tình huống có nguy cơ gây ra sự cố (Near-miss) thì chỉ có 65,9\% NVYT "Báo cáo SS có thể gây hại cho NB nhưng may mắn không gầy hại" (D3).

Bảng 3.10 Tỷ lệ các tiểu mục thuộc yếu tố "Làm việc nhóm giữa các khoa phòng"

\begin{tabular}{|c|c|c|c|c|c|c|}
\hline \multirow{2}{*}{ Nội dung } & \multicolumn{2}{|c|}{ Không đồng ý } & \multicolumn{2}{|c|}{ Khống ý kiến } & \multicolumn{2}{|c|}{ Đồng ý } \\
\hline & $\mathbf{n}$ & $\%$ & $n$ & $\%$ & $\mathbf{n}$ & $\%$ \\
\hline $\begin{array}{c}\text { F4 - Có sự phối hợp tốt giữa các khoa } \\
\text { phòng liên quan }\end{array}$ & 30 & 8,4 & 64 & 17,9 & 263 & 73,7 \\
\hline $\begin{array}{c}\text { F10 - Các KP phối hợp tốt để đảm bảo } \\
\text { chăm sóc NB tốt nhất }\end{array}$ & 18 & 5,0 & 50 & 14,0 & 289 & 81,0 \\
\hline F2R-Các KP không phối hợp tốt với nhau & 86 & 24,1 & 107 & 30,0 & 164 & 45,9 \\
\hline $\begin{array}{c}\text { F6R - NVYT không thoải mái khi làm việc } \\
\text { với NV KP khác }\end{array}$ & 53 & 14,8 & 107 & 30,0 & 197 & 55,2 \\
\hline
\end{tabular}

Đã có 73,7\% NVYT cho rằng: "Có sư phối hợp tốt giữa các khoa phòng liên quan" (D3) và 81,0\% đồng ý: "Các khoa phòng phối hợp tốt để đảm bảo chăm sóc NB tốt nhất" (F10). Nhưng vẫn có Tỷ lệ lớn cho rằng: "Các khoa phòng không phối hợp tốt với nhau" và "NVYT không thoải mái khi làm việc với nhân viên khoa phòng khác" (F2R $=45,9 \%$ và $F 6 R=55,2 \%)$.

Bảng 3.11 Tỷ lệ các tiếu mục thuộc yếu tố "Bảo đám nguồn nhân lực"

\begin{tabular}{|c|c|c|c|c|c|c|}
\hline \multirow{2}{*}{ Nội dung } & \multicolumn{2}{|c|}{ Không đồng ý } & \multicolumn{2}{|c|}{ Không ý kiến } & \multicolumn{2}{|c|}{ Đồng ý } \\
\hline & $\mathbf{n}$ & $\%$ & $\mathbf{n}$ & $\%$ & $\mathbf{n}$ & $\%$ \\
\hline A2-KP có đủ nhân lực đảm bảo công việc & 129 & 36,1 & 61 & 17,1 & 167 & 46,8 \\
\hline $\begin{array}{c}\text { A5R - Tăng thời gian làm việc là cách tốt } \\
\text { để chăm sóc NB }\end{array}$ & 218 & 61,1 & 91 & 25,5 & 48 & 13,4 \\
\hline $\begin{array}{l}\text { A7R - Tăng NVYT trong thời điếm đông } \\
\text { bệnh là cách tốt để chăm sóc NB }\end{array}$ & 109 & 30,5 & 120 & 33,6 & 128 & 35,9 \\
\hline $\begin{array}{l}\text { A14R - NV làm việc theo cách làm thât } \\
\text { nhanh do đó có thể bỏ qua vấn đề ATiNB }\end{array}$ & 69 & 19,3 & 68 & 19,1 & 220 & 61,6 \\
\hline
\end{tabular}

Về vấn đề nhân lực thì 46,8\% NVYT đồng ý "Khoa phòng có đủ nhân lực đảm bảo công việc" (A2) và 35,9\% cho rằng: "Tăng NVYT trong thời điêm đông bênh là cách tốt để chăm sóc NB" (A7R). Chỉ có $13,4 \%$ đồng ý "Tăng thời gian làm việc là cách tốt để chăm sóc NB" (A5R) và có hơn nửa quan niệm: "Nhân viên làm việc theo cách làm thật nhanh do đó có thể bỏ qua vấn đề ATNB" (A14R = 61,6\%).

Bảng 3.12 Tỷ lệ các tiểu mục thuộc yếu tố "Bàn giao và chuyển bệnh"

\begin{tabular}{|c|c|c|c|c|c|c|}
\hline \multirow{2}{*}{ Nội dung } & \multicolumn{2}{|c|}{ Không đồng ý } & \multicolumn{2}{|c|}{ Khống ý kiến } & \multicolumn{2}{|c|}{ Đồng ý } \\
\hline & $n$ & $\%$ & $n$ & $\%$ & $\mathbf{n}$ & $\%$ \\
\hline $\begin{array}{c}\text { F3R - Có nhiều bỏ sót khi chuyến NB } \\
\text { tữ khoa này sang khoa khác }\end{array}$ & 93 & 26,0 & 133 & 37,3 & 131 & 36,7 \\
\hline $\begin{array}{l}\text { F5R - Thông tin chăm sóc NB không } \\
\text { được bàn giao đầy đủ giữa các ca trực }\end{array}$ & 48 & 13,4 & 90 & 25,2 & 219 & 61,4 \\
\hline $\begin{array}{l}\text { F7R - Nhiều vấn đề thường xảy ra } \\
\text { trong trao đổi thông tin giữa các KP }\end{array}$ & 111 & 31,1 & 154 & 43,1 & 92 & 25,8 \\
\hline $\begin{array}{c}\text { F11R - Bàn giao ca trực là vấn đề } \\
\text { đáng lo ngại đối với ATNB }\end{array}$ & 44 & 12,3 & 87 & 24,4 & 226 & 63,3 \\
\hline
\end{tabular}


Có đến 36,7\% NVYT ý kiến: "Có nhiều bỏ sót khi chuyển NB từ khoa này sang khoa khác" (F3R) và $61,3 \%$ cho rằng: "Thông tin chăm sóc NB không được bàn giao đầy đủ giữa các ca trực" (F5R). Gần 1/3 NVYT ý kiến: "Nhiều vấn đề thường xảy ra trong trao đổi thông tin giữa các khoa phòng" và gần $2 / 3$ cho rằng: "Bàn giao ca trực là vấn đề đáng lo ngại đối với $A T N B$ " (F7R $=25,8 \%$ và $F 11 R=$ $63,3 \%)$.

Bảng 3.13 Tỷ lệ các tiểu muc thuộc yếu tố "Văn hóa không đổ lối khi có sai sót"

\begin{tabular}{|c|c|c|c|c|c|c|}
\hline \multirow{2}{*}{ Nội dung } & \multicolumn{2}{|c|}{ Không đồng ý } & \multicolumn{2}{|c|}{ Không ý kiến } & \multicolumn{2}{|c|}{ Đồng ý } \\
\hline & $\mathbf{n}$ & $\%$ & $\mathbf{n}$ & $\%$ & $\mathbf{n}$ & $\%$ \\
\hline A8R - NV lo sợ bị kh & 86 & 24,0 & 148 & 41,5 & 123 & 34,5 \\
\hline $\begin{array}{l}\text { A12R - Khi có SS mọi } \\
\text { hơn là tìm nguyên nh }\end{array}$ & 95 & 26,6 & 95 & 26,6 & 167 & 46,8 \\
\hline $\begin{array}{c}\text { A16R - NV lo lắng những SS sẽ ghi lại trong hồ } \\
\text { sơ cá nhân }\end{array}$ & 173 & 48,5 & 88 & 24,6 & 96 & 26,9 \\
\hline
\end{tabular}

Hơn 1/3 NVYT quan niệm: "Nhân viên lo sợ bi khiển trách khi mắc sai sót" ( $\mathrm{A} 8 \mathrm{R}=34,5 \%)$ và gần phân nửa cho rằng: "Khi có sai sót mọi người nghĩ đến cá nhân hơn là tìm nguyên nhân và biện pháp cải thiện" $(\mathrm{A} 12 \mathrm{R}=46,8 \%)$. Nghiên cứu cũng chỉ ra số lượng không nhỏ $(26,9 \%)$ quan niệm: "Nhân viên lo lắng những sai sót sẽ ghi lại trong hồ sơ cá nhân" (A16R).

\section{BÀN LUẬN}

Các kết quả về làm việc nhóm của nghiên cứu này cao hơn của MV Rao (8)và không khác biệt với BV Từ Dũ (9)

So sánh với nghiên cứu của tác giả MV Rao (8)và Trần Nguyển Như Anh (9)thì kết quả về quan điểm an toàn của lãnh đạo trong nghiên cứu này cao hơn của MV Rao và tương đươn nghiên cứu của Trân Nguyễn Như Anh tại BV Từ Dũ.

Các kết quả về học tập và cải tiến liên tục tương đương nghiên của Trần Nguyễn Như Anh (9) tại BV Từ Dũ.

So sánh với nghiên cứu của tác giả Trân Nguyễn Như Anh (9)tại BV Từ Dũ thì kết quả của về hỗ trợ người bệnh.

Với kết quả quan điểm chung về an toàn người bệnh và phản hồi về các sai sót, phản hồi trao đổi cởi mở về các sai sót thì kết của nghiên cứu này thấp hơn nghiên cứu của tác giả Trần Nguyễn Như Anh (9)

Với báo cáo sai sót tỷ lệ tiểu mục $D 2$ và $D 3$ của nghiên cứu chúng tôi cao hơn nghiên cứu tại BV Tữ Dũ (9), nghiên cứu này có tỳ lệ hỗ trợ hỗ trợ giữa các khoa phòng khá cao so với nghiên cứu của Trần Nguyễn Như Anh tại BV Từ Dũ (9) trong khi có các mục đảm bảo nguồn nhân lực, bàn giao và vận chuyển người bệnh, văn hoá đổ lỗi khi có sai sót lại thấp hơn.

\section{KẾT LUÂ̂N}

Hầu hết lãnh đạo các khoa phòng quan tâm

công tác an toàn người bệnh (ATNB); Đa số NVYT có tinh thần làm việc nhóm, tự học hỏi và hỗ trợ xử trí các vấn đề ATNB trong khoa; $1 / 3$ NVYT cho rằng khoa phòng mình có vấn đề về ATNB; Công tác phản hồi về những sai sót, tỉ lệ trao đổi cởi mở về ATNB và báo cáo sai sót còn chưa nhiều; Làm việc nhóm giữa các khoa chưa thuận lợi; $1 \frac{1}{2}$ NVYT lo ngại khi bàn giao chuyển người bệnh khi xảy ra sự cố; Xấp xỉ 50\% NVYT đánh giá khoa phòng mình là an toàn và thiếu nhân lực.

\section{TÀI LIỆU THAM KHẢO}

1. Sorra J, Gray L, Streagle S, et al. (2016), AHRQ Hospital Survey on Patient Safety Culture: User's Guide, AHRQ Publication, Rockville, pp.

2. Bố Y tế (2014), Tâi liêu đào tạo liên tục về ATNB https://kcb.vn/vanban/tai-lieu-dao-tao-lien-tuc-vean-toan-nguoi-benh

3. Agency for Healthcare Research and Quality (2014), Hospital Survey on Patient Safety Culture: Items and Dimensions, Content last reviewed June 2014. Available from http://www.ahrq.gov/ professionals/quality-patient-safety/

patientsafetyculture/ hospital/userguide/ hospdim.html, accessed 5/3/2017.

4. E M Schimmel (1964), "The hazards of hospitalization", Annals of Internal Medicine, 60,pp. 100-110.

5. $K$ Steel, $P$ M Gertman, C Crescenzi, J Anderson (1981), "Iatrogenic illness on a general medical service at a university hospital", New England Journal of Medicine, 304,pp. 638-642.

6. Reason J. (1990), Human Error, Cambridge University Press, New York, pp.

7. MV Rao, Dayakar Thota, $P$ Srinivas (2014), "A Study to Assess Patient Safety Culture amongst a Category of Hospital Staff of a Teaching Hospital", Journal of Dental and Medical Sciences, 13(3),pp. 16-22.

8. Yanli Nie, Xuanyue Mao, Hao Cui, Shenghong He, Jing Li, Mingming Zhang (2013), "Hospital survey on patient safety culture in China", BMC Health Services Research, 13(228).

9. Trân Nguyê̂n Như Anh' (2015), Nghiên cứu văn hóa ATNB tại Bệnh viện Tứ Dũ, Luận văn Thạc sỹ kinh tế, Trườing Đại học Kinh tế TP. Hồ Chí Minh, pp. 